\title{
Good outcome in isolated basilar artery dissection
}

\author{
Yordan Spirdonov ${ }^{1}$, Plamen Getsov ${ }^{1}$, Grigorii Nedelkov ${ }^{1}$, Evguenia Vassileva ${ }^{2, ~ *, ~ M a r k o ~ K l i s s u r s k i ~}{ }^{2}$, \\ Marin Daskalov ${ }^{2}$
}

${ }^{1}$ Department of Radiology, University Hospital "Tsaritsa Yoanna-ISUL” Sofia, Bulgaria

${ }^{2}$ Department of Neurology, University Hospital "Tsaritsa Yoanna-ISUL” Sofia, Bulgaria

\section{Email address:}

dspirdonov@abv.bg (Y. Spirdonov) plamengecov@abv.bg (P. Getsov)

\section{To cite this article:}

Yordan Spirdonov, Plamen Getsov, Grigorii Nedelkov, Evguenia Vassileva, Marko Klissurski, Marin Daskalov. Good Outcome in Isolated Basilar Artery Dissection. Science Journal of Clinical Medicine. Vol. 4, No. 2, 2015, pp. 26-28. doi: 10.11648/j.sjcm.20150402.11

\begin{abstract}
Isolated basilar artery dissection is a rare vascular pathology with varied clinical presentations and prognoses. We report a case of a 54-year-old woman, presented with subarachnoid hemorrhages (Hunt-Hess grade II). Brain computed tomography demonstrated a perimesencephalic pattern of haemorrhage. Magnetic resonance angiography revealed an isolated basilar artery dissection. Conservative treatment was performed. A complete resolution of the clinical symptoms occurs over a period of 30 days. There was no recurrent haemorrhage. On a follow-up magnetic resonance angiography three months later, a complete resolution of the intramural haematoma in the basilar artery was demonstrated. Some of the cases of basilar artery dissection with perimesencephalic pattern of subarachnoid haemorrhages could have a good prognosis, and could be treated conservatively.
\end{abstract}

Keywords: Basilar Artery Dissection, Perimesencephalic Subarachnoid Haemorrhage, Colour Coded Duplex Sonography

\section{Introduction}

Isolated basilar artery dissection is an extremely rare disease. In most of the cases, the basilar dissection develops as an extension of the dissection of the vertebral artery [1]. The frequency of the isolated basilar artery dissection is 0.25 per 100000 person/years [2]. It is responsible for $1.0 \%$ of subarachnoid haemorrhages, for $10.5 \%$ of posterior circulation dissections, and for $4.5 \%$ of all brain-supplying artery dissections [2]. Clinical presentation and final prognosis of isolated basilar artery dissection are variable. The patients without subarachnoid haemorrhage have a better functional outcome than those with subarachnoid haemorrhage [3]. We report a case of isolated basilar artery dissection in a patient presented with subarachnoid haemorrhage, a relatively benign course of the disease and a favorable outcome.

\section{Case Report}

A 54-year-old woman with arterial hypertension of short duration was admitted to our hospital with a sudden severe headache followed by nausea and vomiting. The patient had no past medical history of headache or warning signs in the days or weeks preceding the symptom onset. There was no history of trauma or previous neurological disease. On neurological examination, a mild degree of neck stiffness without any other neurological deficit was found. The patient underwent a computed tomography of the brain that revealed a haemorrhage, located behind the clivus and along the basilar artery (Fig. 1).

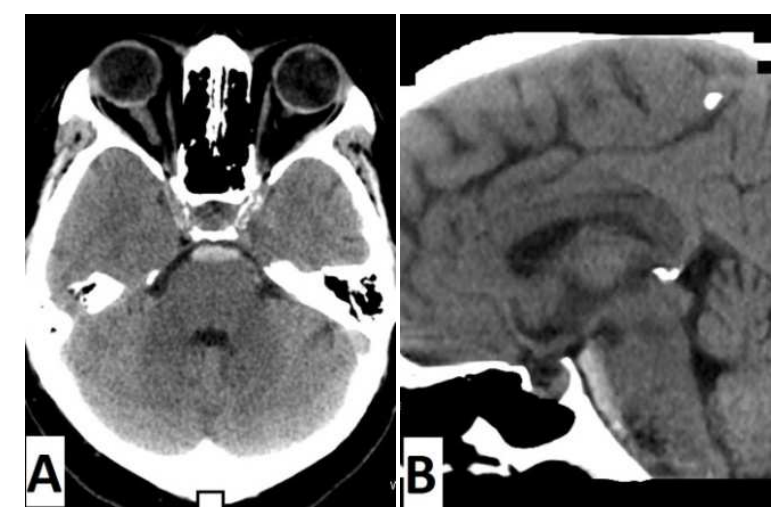

Fig. 1. Computed tomography of the brain demonstrates haemorrhage in the prepontine cistern area $(A)$ and along the entire basilar artery $(B)$.

Colour coded duplex sonography of extracranial carotid and vertebral arteries did not reveal pathological structural and haemodynamic changes. Transcranial colour duplex 
sonography showed normal flow velocities in the intracranial part of the vertebral arteries and in the basilar artery.

On magnetic resonance imaging, and on magnetic resonance angiography, an irregular narrowing of the lumen of the basilar artery was disclosed due to intramural haematoma in the wall of the artery (Fig.2).

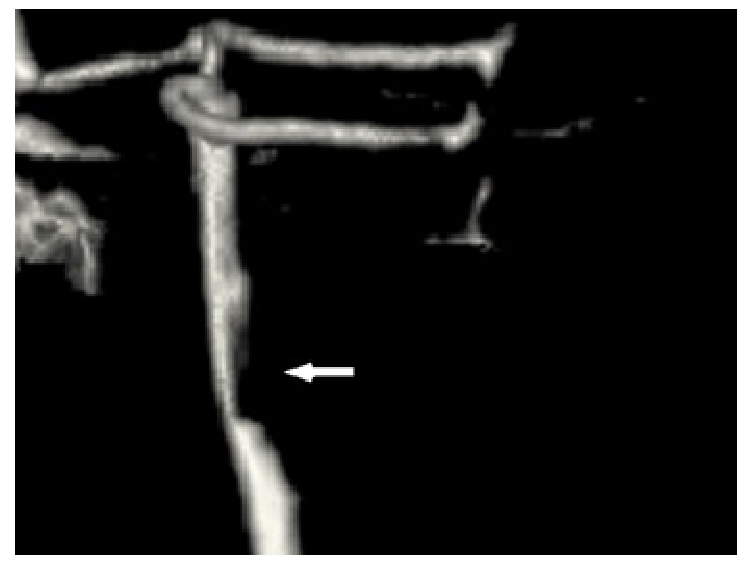

Fig. 2. Magnetic resonance angiography - an irregular narrowing of the lumen of the basilar artery. The outline of the vessel is interrupted by intramural haematoma.

Cerebrospinal fluid examination was consistent with subarachnoid haemorrhage. There was no evidence of thrombocytopenia or other coagulopathy, on laboratory bloodtesting. A conservative treatment with analgesics and anti-hypertensive drugs was carried out. A complete resolution of the clinical symptoms occurs over a period of 30 days. There was no recurrent haemorrhage. On a follow-up magnetic resonance angiography three months later, a complete resolution of the intramural haematoma in the wall of the basilar artery was demonstrated (Fig. 3).

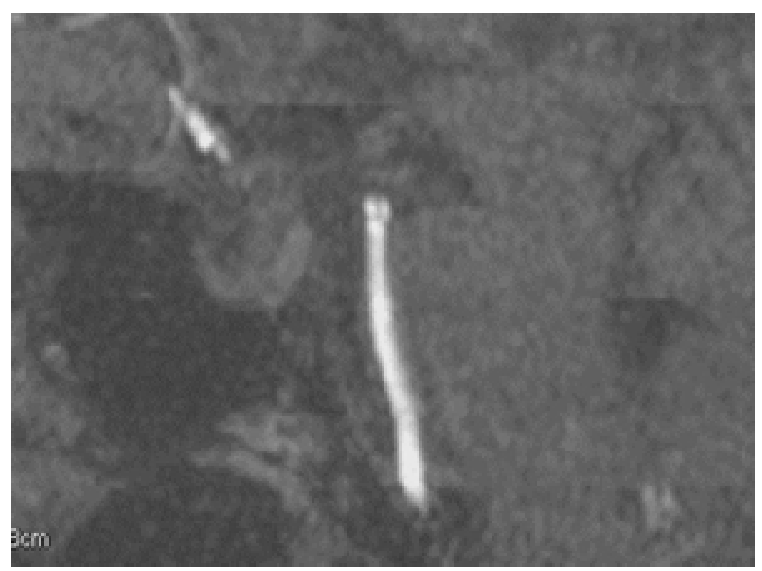

Fig. 3. Magnetic resonance angiography three months later - full recovery of the lumen of the basilar artery.

\section{Discussion}

The severity of initial haemorrhage in the cases with basilar artery dissection is one of the main factors that strongly influence the outcome. More commonly, a massive subarachnoid haemorrhage with tamponade of large portions of the subarachnoid space occurs, being indistinguishable from that observed in the cases with aneurysmal bleeding [2]. Mortality of ruptured basilar dissection is high. It ranges from $30 \%$ [4] to $78.9 \%$ [5].

In our case, the localization of the bleeding was along the pons (in the prepontine, interpeduncular cistern), with a haemorrhage of relatively small volume closely attached along to the basilar artery. In the clinical practice the prognosis of subarachnoid haemorrhage is significantly better in patients with perimesencephalic non-aneurysmal subarachnoid haemorrhage than those with other types of haemorrhages [6, 7]. A perimesencephalic subarachnoid haemorrhage had an arterial origin in approximately $5 \%$ of the patients, as reported previously in many angiography studies [8-10].

The outcome of subarachnoid haemorrhage due to basilar artery dissection is dependent on several factors, such as an occurrence of recurrent bleeding and the evolution of vascular lesion [3, 4]. A relapse of subarachnoid haemorrhage occurs mainly in the acute phase of the disease, and rarely in the coming months and years [2]. A spontaneous and complete recovery of the vascular lesion, such as we observed, has been rarely reported [11-15].

Findings of colour coded duplex sonography were not diagnostic or specific to the present disease case. Colour coded duplex sonography could have a diagnostic value in the cases of high-grade basilar obstruction or cerebral vasospasm. Our observation showed that in the cases of a low or moderate-grade stenotic intramural haematoma, the basilar artery could be visualized with normal blood flow velocities.

\section{Conclusion}

The isolated basilar artery dissection is a rare vascular pathology with varied clinical presentations. Some of the cases of basilar artery dissection with perimesencephalic pattern of subarachnoid haemorrhage on computed tomography could have a good prognosis and could be treated conservatively.

\section{References}

[1] Mokri B, Houser OW, Sandok BA, Piepgras D. Spontaneous dissections of the vertebral arteries. Neurology 1988; 38: 880-885.

[2] Ruecker M, Furtner M, Knoflach M, Werner P, Gotwald T, Chemelli A, Zangerle A, Prantl B, Matosević B, Schmidauer C, Schmutzhard E, Willeit J, Kiechl S. Basilar artery dissection: series of 12 consecutive cases and review of the literature. Cerebrovasc Dis 2010; 30: 267-276.

[3] Kim CH, Son YJ, Paek SH, Han MH, Kim JE, Chung YS, Kwon BJ, Oh CW, Han DH. Clinical analysis of vertebrobasilar dissection.Acta Neurochir (Wien)2006; 148: 395-404.

[4] Kim BM, Suh SH, Park SI, Shin YS, Chung EC, Lee MH, Kim EJ, Koh JS, Kang HS, Roh HG, Won YS, Chung PW, Kim YB, Suh BC. Management and clinical outcome of acute basilar artery dissection. AJNR Am J Neuroradiol 2008; 29: 1937- 4. 
[5] Masson C, Krespy Y, Masson M, Colombani JM. Magnetic resonance imaging in basilar artery dissection. Stroke 1993; 24 : 1264-1266.

[6] Cánovas D, Gil A, Jato M, de Miquel M, Rubio F. Clinical outcome of spontaneous non-aneurysmal subarachnoid hemorrhage in 108 patients. European Journal of Neurology 2012; 19: 457-61.

[7] Gijn JV, Rinkel GJ. Subarachnoid haemorrhage: diagnosis, causes and management. Brain 2001; 124: 249-278.

[8] Rinkel GJ, Wijdicks EF, Vermeulen M, Ramos LM, Tanghe HL, Hasan D et al. Nonaneurysmal perimesencephalic subarachnoid hemorrhage: $\mathrm{CT}$ and MR patterns that differ from aneurysmal rupture. AJNR Am J Neuroradiol 1991; 12: 829-34.

[9] Pinto AN, Ferro JM, Canhao P, Campos J. How often is a perimesencephalic subarachnoid haemorrhage CT pattern caused by ruptured aneurysms? Acta Neurochir (Wien) 1993; 124: 79-81.

[10] Van Calenbergh F, Plets C, Goffin J, Velghe L. Nonaneurysmal subarachnoid hemorrhage: prevalence of perimesencephalic hemorrhage in a consecutive series. Surg Neurol 1993; 39: $320-3$.

[11] Ross GJ, Ferraro F, DeRiggi L, Scotti LN. Spontaneous healing of basilar artery dissection: MR findings. J Comput Assist Tomogr 1994; 18: 292-294.

[12] Pozzati E, Andreoli A, Padovani R, Nuzzo G. Dissecting aneurysms of the basilar artery. Neurosurgery 1995; 36: 254-258.

[13] Yoshimoto Y, Hoya K, Tanaka Y, Uchida T. Basilar artery dissection. J Neurosurg 2005; 102: 476-481.

[14] Woimant F, Spelle L. Spontaneous basilar artery dissection: contribution of magnetic resonance imaging to diagnosis. J Neurol Neurosurg Psychiatry 1995; 58: 540.

[15] Ahn SS, Kim BM, Suh SH, Kim DJ, Kim DI, Shin YS, Ha SY, Kwon YS. Spontaneous Symptomatic Intracranial Vertebrobasilar Dissection: Initial and Follow-up Imaging Findings.Radiology 2012; 264: 196-202. 